\title{
SYNTHESIS OF OLIGONUCLEOTIDES BEARING AN ARYLAMINE MODIFICATION IN THE C8-POSITION OF 2'-DEOXYGUANOSINE
}

\author{
C. Meier and S. GräsI $\square$ Institute of Organic Chemistry, University of Hamburg, \\ Germany \\ I. Detmer and A. Marx $\square$ Fachbereich Chemie, University of Konstanz, Konstanz, \\ Germany
}

\begin{abstract}
C8 Arylamine $d G$ adducts were converted into their corresponding $5^{\prime} O D M T r 3^{\prime} O$ phosphorami dite $C 8$ arylamine $d G$ derivatives. These compounds were used for the automated synthesis of site specifically modified oligonucleotides. The oligonucleotides were studied for their CD properties, $T_{m}$ values, and their effects on primer extension assays using human DNA polymerase $\beta$.
\end{abstract}

Keywords DNA Damage, C8 Arylamine Adducts, Chemical Carcinogenesis, Mutations

\section{INTRODUCTION}

Instead of 2-aminofluorene, 1- or 2-naphthylamine, monocyclic aromatic amines like anisidine belong to the class of borderline carcinogens. However, both groups led after metabolic activation predominately to the formation of the same type of covalent DNA-product: the C8-arylamine-2'-deoxyguanosine adduct (C8ArNH-dG).$^{[1]}$ The extent of DNA-damage from both classes of carcinogens is comparable. If these DNA-damages are not repaired, they can compromise the fidelity of DNA replication and cause mutations and possibly cancer. So far the difference of the effects caused by strong carcinogens and the borderline carcinogens on DNA-related processes is not known. To study the biochemical effects, structure and repair of these adducts, a strategy for the site-specific incorporation of dG-carcinogen adducts into oligonucleotides is needed. So far, modified oligonucleotide strands have been prepared by post-synthetic treatment with electrophilic amination reagents, ${ }^{[2]}$ resulting in very low amounts of the oligonucleotides $(1-5 \%$ yield $) .{ }^{[3]}$ Due to the low yields, this procedure is therefore only applicable for one $\mathrm{dG}$ containing oligonucleotide sequences. A better way

Address correspondence to C. Meier, Institute of Organic Chemistry, University of Hamburg, Martin Luther King Platz 6, Hamburg D 20146, Germany. 
would be a strategy for a site-specific incorporation of the modified dG using the phosphoramidite approach.

\section{RESULTS}

Recently we published a highly efficient synthetic protocol for the synthesis of the C8-arylamine-dG adducts using a palladium-catalyzed Buchwald-Hartwig crosscoupling reaction ${ }^{[4]}$ The heteroaromatic system should be appropriately protected for the metal-catalyzed cross-coupling. Therefore, we used the electron-withdrawing iso-butyryl-group at the exocyclic amino group and the benzyl or cyanophenylethyl (CPE) protection group at the $\mathrm{O}^{6}$-position. Without the latter protecting group, the cross-coupling was unsuccessful. Adducts of different aromatic and heteroaromatic systems have been prepared in $60-80 \%$ yield. Subsequently, the adducts were converted into the corresponding phosphoramidites. The synthesis is briefly summarized in Figure 1.

Using these phosphoramidites, numerous oligonucleotides bearing one anilinyl-, toluidinyl-, anisidinyl-, or aminobiphenyl-dG adduct have been prepared by standard oligonucleotide synthesis on a CPG support. Three cycles of arylamineadduct phosphoramidite addition were used and the coupling periods were extended to $60 \mathrm{~s}$. Cleavage of the oligonucleotides from the solid support has been done with aqueous ammonia in the presence of mercaptoethanol because these adducts are base-labile. Purification of the adduct containing oligonucleotides has been performed by HPLC using a DMTr-off protocol and a Waters X-Terra column. The oligonucleotides have been studied for purity by HPLC analysis and were characterized by MALDI-mass spectrometry.

Then, $T_{m}$ values of the homo-thymidine oligonucleotides bearing one modified $\mathrm{dG}$ in the center hybridized with oligo-dA strand bearing all four different bases opposite to the modification site were determined. The $T_{m}$ value of a reference $(\mathrm{T})_{7}(\mathrm{dG}) \mathrm{T}_{7} \cdot(\mathrm{dA})_{7}(\mathrm{dC})(\mathrm{dA})_{7}$ duplex was found to be $39.4^{\circ} \mathrm{C}$. A considerable decrease in the $T_{m}$ was found when the $d G$ was replaced by the arylamine-adduct. The highest $T_{m}$ value for the adduct-bearing oligonucleotide was measured if a $\mathrm{dC}$
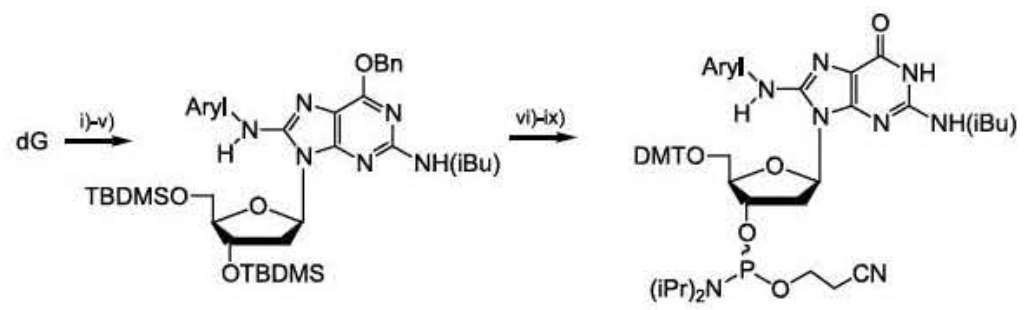

i) NBS, $\mathrm{H}_{2} \mathrm{O}, \mathrm{rt}, 15 \mathrm{~min}$; ii) TBDMSCl, imidazole, pyridine, $1 \mathrm{~h}$; iii) $\mathrm{PhCH}_{2} \mathrm{OH}, \mathrm{PPh}_{3}$, DIAD, 1,4-dioxane, $\mathrm{rt}, 1 \mathrm{~h}$; iv) iBu-chloride, pyridine, $\mathrm{it}, 1 \mathrm{~h} ; \mathrm{v}$ ) arylamine, $\mathrm{Pd}_{2}(\mathrm{DBA})_{3}(10 \mathrm{~mol} \%), \mathrm{K}_{3} \mathrm{PO}_{4}$, rac. BINAP $(30 \mathrm{~mol} \%), 1,2$-dimethoxyethane, $\left.80^{\circ} \mathrm{C}, 50 \mathrm{~h} ; \mathrm{vi}\right) \mathrm{Pd} / \mathrm{C}$, $\mathrm{MeOH}, \mathrm{rt}, 45 \mathrm{~min}$; vii) TBAF, THF, it, $3 \mathrm{~h}$; viii) DMT-Cl, pyridine, it, $3 \mathrm{~h}$; ix) bis(di-i-propylamino)-2-cyanoethyl-phosphine, 1H-tetrazole, $\mathrm{C}_{6} \mathrm{H}_{6} / \mathrm{CH}_{3} \mathrm{CN}$ i:1, rt, $3 \mathrm{~h}$.

FIGURE 1 Synthesis of the arylamine adduct phosphoramidites. 
TABLE $1 \mathrm{~T}_{\mathrm{m}}$ Values of the $\mathrm{T}_{7}$ (Arylamine $\left.\mathrm{dG}\right) \mathrm{T}_{7} \cdot \mathrm{dA}_{7} \mathrm{XdA}_{7}$ Hybrid

\begin{tabular}{lcccr}
\hline & \multicolumn{4}{c}{$\mathrm{T}_{\mathrm{m}}$ value $\left({ }^{\circ} \mathrm{C}\right)$ against $\mathrm{dA}_{7} \mathrm{XdA}_{7}$} \\
\cline { 2 - 5 } Oligonucleotide & $\mathrm{X}=\mathrm{C}$ & $\mathrm{X}=\mathrm{G}$ & $\mathrm{X}=\mathrm{T}$ & $\mathrm{X}=\mathrm{A}$ \\
\hline TTTTTTT(dG)TTTTTTT & 39.4 & 28.6 & 30.1 & 27.7 \\
TTTTTTT(Tol dG) TTTTTTT & 34.9 & 27.3 & 28.4 & 26.2 \\
TTTTTTT(ABP dG) TTTTTTT & 32.8 & 25.7 & 26.6 & 25.4 \\
\hline
\end{tabular}

nucleotide was present in the opposite strand $\left(\mathrm{T}_{\mathrm{m}}=34.9^{\circ} \mathrm{C}\right.$ and $32.8^{\circ} \mathrm{C}$ for the toluidine and the aminobi phenyl-adduct, respectively). In the case of the toluidine adduct, $T_{m}$ values dropped further when $d G$ or $d A$ was placed opposite to the adduct. Such an effect was also observed in the case of the reference oligo hybrid. However, in the case of the aminobi phenyl adduct, the $T_{m}$ was independent to the nucleotide opposite to the adduct (Table 1).

Next, a mixed sequence 15-mer-oligonucleotide was used. Here, different arylamine-adducts were incorporated in the middle while in the opposite strand always $\mathrm{dC}$ was placed. The unmodified hybrid showed a $\mathrm{T}_{\mathrm{m}}$ value of $51.6^{\circ} \mathrm{C} . \mathrm{T}_{\mathrm{m}}$ values of the modified 15 -mers were found to be $46.3^{\circ} \mathrm{C}$ (anilinyl-), $46.4^{\circ} \mathrm{C}$ (toluidinyl-), 45.0 (aminobi phenyl-), and $46.3^{\circ} \mathrm{C}$ (anisidinyl-adduct). Again, one modification only was responsible for a considerable loss of thermal stability of the duplex. Interestingly, the effect of the strong carcinogen aminobi phenyl was only slightly stronger as compared to the borderline carcinogens aniline, toluidine, and anisidine.

Further structural effects of the incorporation of the adducts into the oligonucleotides were studied using CD-spectroscopy. However, no difference in the CD-spectra was observed for the adduct-bearing oligonucleotides compared to the unmodified case. All curves show shapes found previously for B-type DNA duplexes. No difference between the aminobiphenyl adduct and the monocyclic aromatic amines can be observed. The same $\mathrm{CD}$ properties have been found in the case of the $\mathrm{T}_{7}$ (arylamine-dG) $\mathrm{T}_{7} \cdot \mathrm{dA}_{7} \mathrm{XdA}_{7}$ hybrids. Again, all showed typical shapes for B-type DNA and no difference to the reference hybrid.

Finally, first experiments for primer-template extension studies have been performed. As polymerase, the human enzyme pol $\beta$ has been used. The adduct has been incorporated into a 34-mer template strand. The primer ends directly before the adduct. Thus, standing start conditions were used. Then, all four NTPs were added separately. Only dCTP was incorporated opposite to the arylamine adducts in all cases. However, a futher experiment was performed in which the $\mathrm{dC}$ opposite to the arylamine adduct is already incorporated in the primer. Thus, experiments under standing start +1 conditions where done (Figure 2). Surprisingly, in these experiments DNA pol $\beta$ showed a considerable loss in fidelity!

Thus, errors seem to take place not at the opposite site of the adduct but one step downstream. This effect was most apparent for the aminobi phenyl adduct but was also observed in lower extent for the monocyclic aryl amines. This is an 


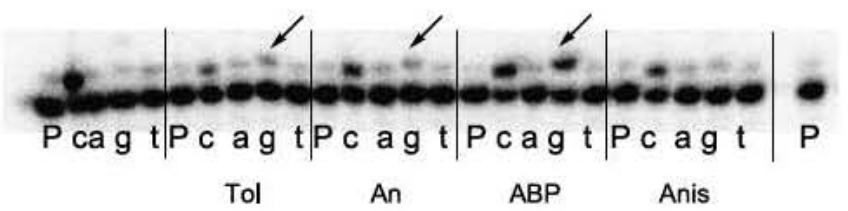

FIGURE 2 Standing start +1 primer extension experiment with DNA polymerase $\beta$.

entirely unexpected result, which may have an important impact on the mutation probability. Further experiments will be done to explain this new and unexpected lack of fidelity in enzymatic DNA synthesis.

\section{REFERENCES}

1. Meier, C.; Boche, G. The modification of guanine nucleosides and nucleotides by the borderline carcinogens 4 methyl and 4 methoxyaniline: chemistry and structural characterisation. Carcinogenesis 1991, 12(6), 1633 1640.

2. Beland, F.A.; Kadlubar, F.F. Formation and persistence of arylamine DNA adducts in vivo. Environ. Health Perspect. 1985, 62, 1936.

3. Shibutani, S.; Fernandes, A.; Suzuki, N.; Zhou, L.; Johnson, F.; Grollman, A.P. Mutagenesis of the $\mathrm{N}$ (deoxyguanosin 8yl) 2 amino 1 methyl 6 phenylimidazo [4,5 b]pyridine DNA adduct in mammalian cells. Sequence context effects. J. Biol. Chem. 1999, 274, 2743327438.

4. Meier, C.; Gräsl, S. Highly efficient synthesis of a phosphoramidite building block of C8 deoxyguanosine adducts of aromatic amines. Synlett 2002, 5, 802804 